\title{
Incomplete Spinal Cord Injury in Enugu, Nigeria: Epidemeology and Outcome
}

\author{
Emmanuel Chino Iyidobi, Remigius Tochukwu Ekwunife, Cajethan Uwatoronye Nwadinigwe, \\ Nduduisi Ebere Duru, Kenechi Anthony Madu, Chidi Nwoga
}

National Orthopedic Hospital, Enugu, Nigeria

Email: dreciyidobi@yahoo.com

How to cite this paper: Iyidobi, E.C., Ekwunife, R.T., Nwadinigwe, C.U., Duru, N.E., Madu, K.A. and Nwoga, C. (2018) Incomplete Spinal Cord Injury in Enugu, Nigeria: Epidemeology and Outcome. Journal of Biosciences and Medicines, 6, 53-60.

https://doi.org/10.4236/jbm.2018.69006

Received: August 22, 2018

Accepted: September 22, 2018

Published: September 25, 2018

Copyright (c) 2018 by authors and Scientific Research Publishing Inc. This work is licensed under the Creative Commons Attribution International License (CC BY 4.0).

http://creativecommons.org/licenses/by/4.0/

c) (i) Open Access

\begin{abstract}
Background: Spinal cord injury represents one of the most physically and psychologically devastating trauma. Before modern medicine, it was considered an ailment not to be treated. In incomplete spinal cord injury (SCI), there is residual sensory and/or motor function. Method: This was to determine the epidemiology, treatment options and outcome of incomplete SCI at National Orthopedic Hospital Enugu, Nigeria, over a 5 year period. This was a descriptive retrospective study of patients managed for incomplete spinal cord injury between January 2011 and December 2015. This was to determine the epidemiology, various treatment options and their outcome in patients with incomplete SCI managed in our center. The patients' biodata, mechanism of injury, time of presentation, pattern of injury, level of injury, type of treatment, associated injuries, complications, duration of treatment and American Spinal Injury Association (ASIA) assessment at presentation and at discharge were collected. Data analysis was done using statistical package for social sciences (SPSS) version 20.0. All tests were regarded as significant at P-values $<0.05$. Results: A total of 57 patients (49 males and 8 females) were included and analyzed showing a male to female ratio of 6.3:1. Incomplete traumatic SCI forms about $44.2 \%$ of all traumatic SCI in Enugu. This represents $0.09 \%$ of all patients and $0.9 \%$ of all trauma patients seen. The cervical spine (59.6\%) is the most commonly affected isolated anatomic region. Road traffic accident (52.6\%) was the most common aeteology. Compression fracture was the commonest injury (33.3\%). Majority of the patients (57.9\%) had ASIA C at presentation while $47.4 \%$ and $33.3 \%$ of the patients had ASIA $\mathrm{D}$ and $\mathrm{E}$ respectively at discharge. Most of the patients (91.2\%) had conservative treatments. Conclusion: The significant ASIA grade improvement of majority of the patients suggests good functional outcome of incomplete SCI treated conservatively at our hospital.
\end{abstract}

\section{Keywords}

Incomplete Spinal Cord Injury, Epidemeology, Outcome 


\section{Introduction}

Spinal cord injury (SCI) represents one of the most physically and psychologically devastating trauma. Before the advent of modern medicine, it was considered as an ailment not to be treated [1]. It often results in life-long functional disability [2] being a medically complex and life disrupting condition [3]. SCI results from disruption of neural elements of spinal cord [4] which is situated within the spinal column and extends from the brain to L1 - L2 vertebral level where it terminates as conus medullaris [3].

Road traffic crashes remain the major cause of the injury worldwide [3]. Violent crimes, sports related falls and penetrating injuries [4] [5] are known to cause SCI. Whatever the aetiology is, there is primary mechanical compression, distraction, laceration and shear forces or secondary extension of ischaemic damage to neural and axonal tissues [6].

In incomplete SCI, there is residual sensory and/or motor function below the level of the injury. The general outcome depends on a number of factors including level and extent of injury, time to presentation and the initial management given to the patient [7] [8]. The incidence of incomplete SCI is increasing because of improved motor vehicular safety and better early care [9] [10] [11]. This was to determine the epidemiology, various treatment options and their outcome in patients with incomplete SCI managed at National Orthopedic Hospital Enugu, South East Nigeria.

\section{Methodology}

This is a descriptive retrospective study of patients managed for incomplete spinal cord injury at National Orthopaedic Hospital Enugu (NOHE) between January 2011 and December 2016. Ethical clearance was obtained from the hospital ethical committee. The accident and emergency admissions and theatre registers were used to identify the folder numbers of patients with incomplete SCI for the period under review. The identified case notes were retrieved from the medical records departments and names matched with the folder numbers to avoid double recruitments. The patients' biodata, mechanism of injury, time of presentation, pattern of injury, level of injury, type of treatment, associated injuries, complications, duration of treatment and American Spinal Injury Association (ASIA) assessment at presentation and at discharge were collected.

The collated data were stored in hard as well as electronic forms. Data analysis was done using statistical package for social sciences (SPSS) version 20.0. Graph pad prism was additionally used as necessary. Descriptive statistics which includes frequency, percent, mean, median, and standard deviation were used to summarize categorical and continuous variables. Associations between categorical variables were analysed using Student-t test and chi-square tests for significance. All tests were regarded as significant at P-values $<0.05$. Results of the analysis were presented in texts, tables and figures as indicated. 


\section{Results}

A total of 57 patients (49 males and 8 females) with complete records were included and analyzed showing a male to female ratio of 6.3:1 (Figure 1). Incomplete traumatic SCI forms about $44.2 \%$ of all traumatic SCI in Enugu. This represents $0.09 \%$ of all patients and $0.9 \%$ of all trauma patients seen within the study period. The most common age bracket at presentation was found to be 31 50 years (49.2\%) (Figure 2). Most of the patients (66.7\% and $24 \%$ ) presented

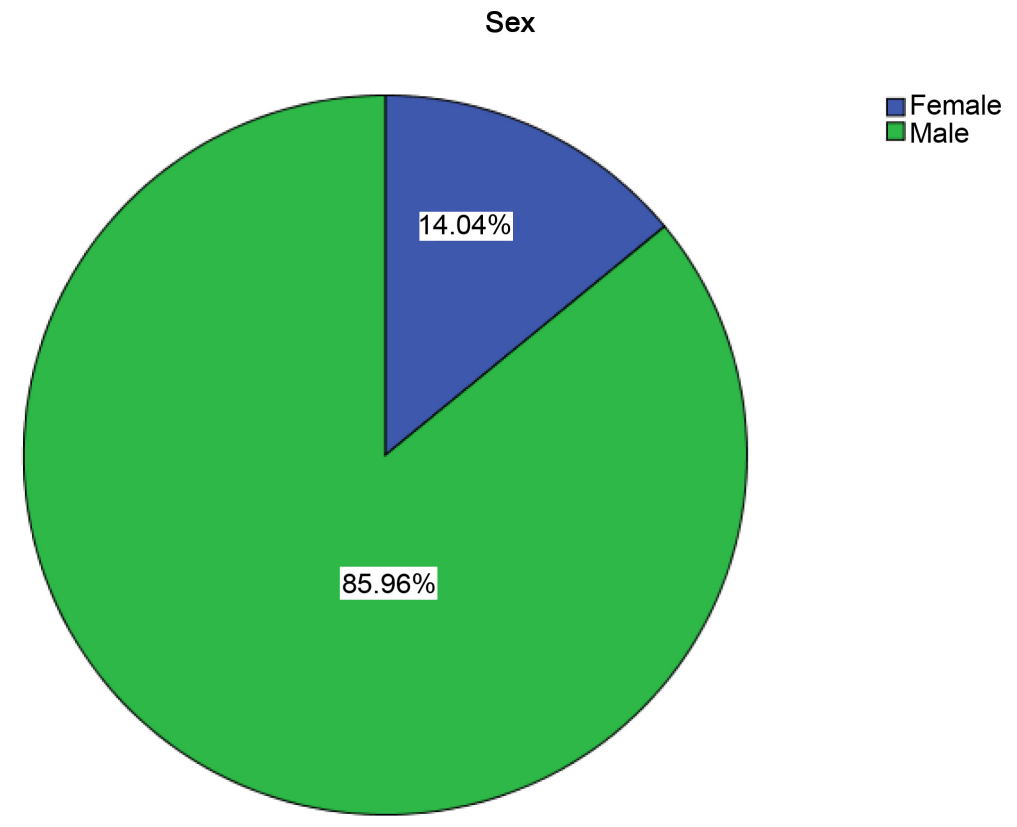

Figure 1. Pie chart of sex distribution of the patients.

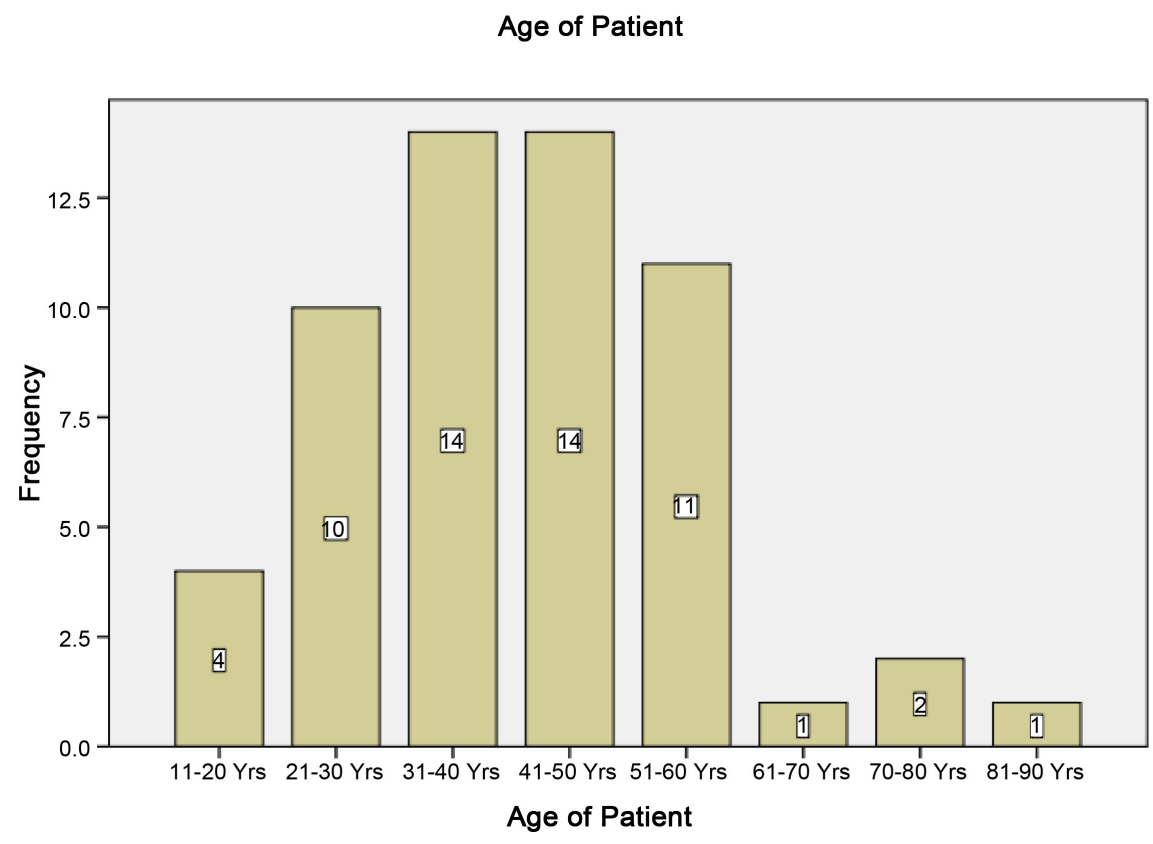

Figure 2. Bar chart of age distribution of patients wih incomplee SCI. 
within one and two weeks of their injury respectively. The cervical spine (59.6\%) is the most commonly affected isolated anatomic region. Affectation of two spinal segments occurred in about 5 patients accounting for only $8.8 \%$ (Table 1 ). Road traffic accident was found to be the most common cause of injury accounting for up to $52.6 \%$ while gunshot injury was the least common aetiology (Table 2). Compression fracture was the most common injury (33.3\%). Other common pathologies include traumatic spondylolisthesis $28.07 \%$, and burst fracture $15.79 \%$ (Figure 3). Isolated traumatic disc prolapse accounted for only $5.26 \%$. Majority of the patients (57.9\%) had ASIA C at presentation while $47.4 \%$ and $33.3 \%$ of the patients had ASIA D and E respectively at discharge, showing statistically significant improvement of the patients at discharge, ( $\mathrm{P}$ value < 0.0001 (Table 3 ). This represents $80.7 \%$ of the patients having at least improvement of one grade of ASIA assessment at discharge. Most of the patients (91.2\%) had conservative treatment in the form of cervical traction with Minerva jacket (54.4\%) and thoracolumbar jacket (31.6\%) while $8.8 \%$ had spinal decompression (Table 4). Majority of the patients (75.5\%) had hospital stay of 1 - 8 weeks. Thirty patients $(52.6 \%)$ managed had no complication. The commonest complications seen were urinary tract infection and pressure sores (Figure 4).

\section{Discussion}

Within the study period, $0.2 \%$ of all the patients that presented in the hospital were cases of traumatic SCI and $44.2 \%$ of the traumatic SCI were incomplete

Table 1. Level of injury.

\begin{tabular}{lcc}
\hline & Frequency & Percent \\
\hline Only Cervical Spine & 31 & 54.4 \\
Only Thoracic Spine & 5 & 8.8 \\
Only Lumbar Spine & 16 & 28.1 \\
Cervical with Thoracic & 3 & 5.3 \\
Thoracic with Lumbar & 2 & 3.5 \\
Total & 57 & 100.0 \\
\hline
\end{tabular}

Table 2. Aetiology of incomplete SCI.

\begin{tabular}{ccc}
\hline & Frequency & Percent \\
\hline RTA & 30 & 52.6 \\
Gun Shot & 1 & 1.8 \\
Fall from Height & 19 & 33.3 \\
Assault & 3 & 5.3 \\
Others: Hit by Object, Dive into Shallow Water & 4 & 7.0 \\
Total & 57 & 100.0 \\
Mean: $2.12 \pm 0.174$, Std. Deviation: 1.310 &
\end{tabular}


Table 3. ASIA scoring at presentation and discharge.

\begin{tabular}{cccccc}
\hline & ASIA at Presentation & \multicolumn{2}{l}{ ASIA at Discharge } & \\
\hline Score & Freq. & Percent & Freq. & Percent & $\begin{array}{c}\text { P value } \\
\text { (two-tailed) }\end{array}$ \\
\hline A & 0 & 0.0 & 0 & 0.0 & \\
B & 7 & 12.3 & 0 & 0.0 & $<0.0001$ \\
C & 33 & 57.9 & 7 & 12.3 & \\
D & 9 & 15.8 & 27 & 47.4 & \\
E & 8 & 14.0 & 23 & 40.4 & \\
Total & 57 & 100.0 & 57 & 100.0 & \\
\hline
\end{tabular}

Approximate $\mathrm{P}$ value $(<0.0001)$ is significant at (alpha $=0.05)$.

Table 4. Type of treatment.

\begin{tabular}{ccc}
\hline Type of treatment given & Frequency & \\
\hline CONS. = Cervical + Minerva Jacket & 6 & 10.5 \\
CONS. = C. Collar, Skull Traction, Minerva Jacket & 25 & 43.9 \\
CONS. = Cervical Collar & 3 & 5.3 \\
CONS. = Thoracolumbar Jacket & 18 & 31.6 \\
Surgical (Spinal Decompression) & 5 & 8.8 \\
Total & 57 & 100.0 \\
Mean: $2.84 \pm 0.164$, Std. Deviation: 1.236 & \\
\hline
\end{tabular}

\section{Pathology}

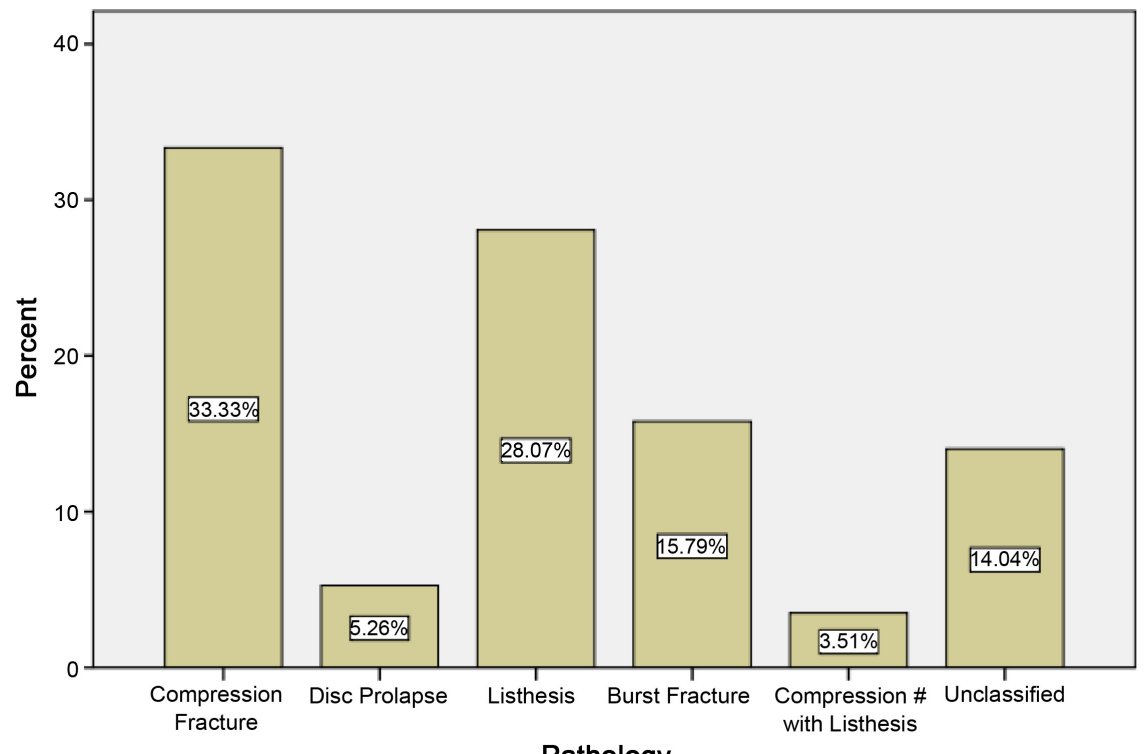

\section{Pathology}

Figure 3. Pathology of incomplete SCI.

injury. This is similar to reports for other developing countries [12]. The study found a male preponderance of the injury which is similar to that reported by 


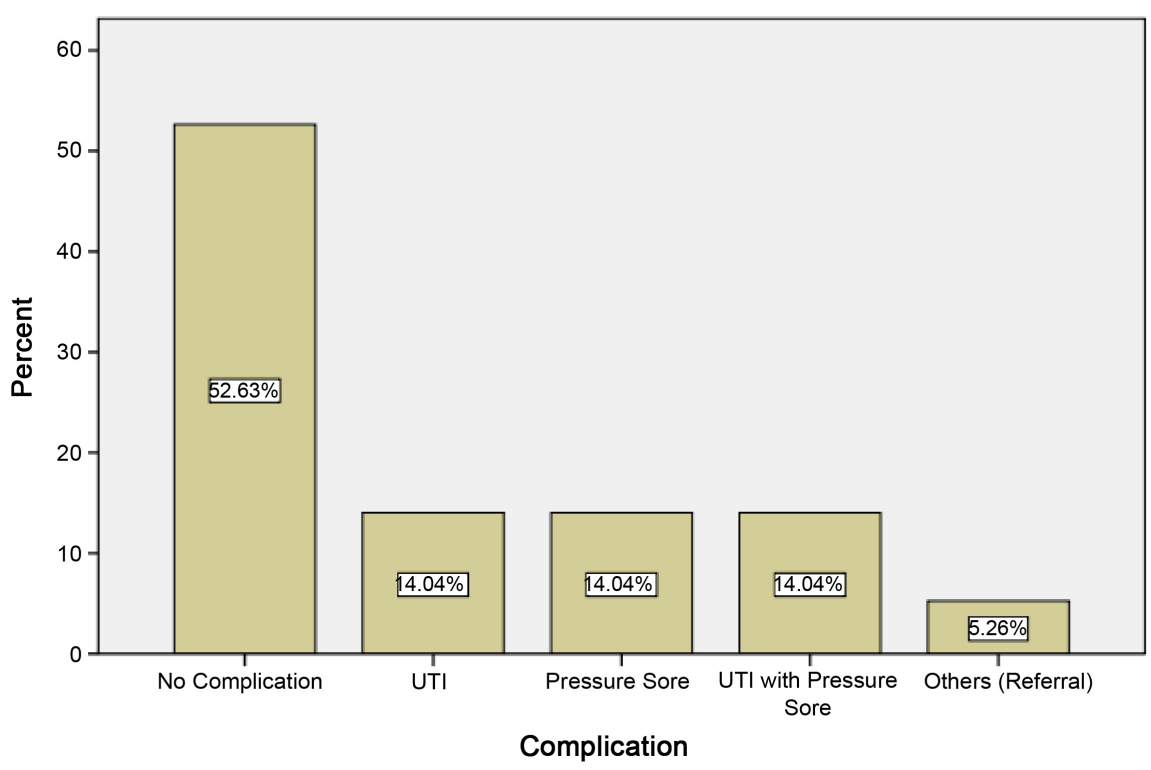

Figure 4. Complications of incomplete.

Ahmad et al. in their study at Yazd city [13]. The mean age of the patients is $41.35 \pm 1.938$ years. The most common affected age bracket of $31-50$ years found in the study was also similar to that reported by Shrestha et al. Shrestha et al. in their study showed age range of between 26 - 56 years as the most commonly affected [14]. This is within the most productive, mobile and exploratory age group. The cervical spine (54.4\%) was the commonest anatomic region of affectation. This is similar to that reported by Kumar et al. (44.1\%) but differed from that of Ahmad et al. that reported thoracic spine as the commonest (44.2\%) [13] [15]. Road traffic accident is the most common cause (52.6\%), followed by a fall from a height (19\%). These were similar to those reported by Ahmad et al. in their study showing motor vehiclar accident and fall from a height as $66.7 \%$ and $15.5 \%$ respectively [13]. However, Conran et al. in their study reported assault as the most common etiology in South Africa (60\%) and fall from a height (58\%) in Sweden [16]. On discharge, $47.4 \%$ of the patients had ASIA D, 33.3\% had ASIA $\mathrm{E}$ and $12.3 \%$ had ASIA C. However, Bartel et al. reported good outcome in conservative management of central cord syndrome patients and that surgery has been found to give a better outcome if done within 24 hours of injury [17]. Study by Hwa et al. showed that $58 \%$ of patient that had laminoplasty for incomplete injury improved by one or more ASIA grade in 6 months [18]. Although, most of the patients in our study (91.2\%) were managed conservatively but at discharge $47.4 \%$ and $33.3 \%$ had ASIA D and E respectively. This was similar to the good outcome reported by Bartel et al. with their conservative management of central cord syndrome. Similarly in our study, even though only $8.8 \%$ had surgical decompression, they also showed good outcome similar to that reported by Hwa et al. in their study [18]. In our work, both the patients managed conserva- 
tively and those who had surgical decompression demonstrated good outcome of neurologic improvement.

\section{Conclusion}

The significant ASIA grade improvement of majority of the patients suggests good functional outcome of incomplete SCI treated conservatively as at National Orthopedic Hospital Enugu.

\section{Conflicts of Interest}

The authors declare no conflicts of interest regarding the publication of this paper.

\section{References}

[1] Malhorta, C.D.R. and Brig, H.B. (2010) Spinal Cord Injuries. MJAFI, 66, 326-328.

[2] Martin, H.P. (1983) Spinal Cord Injury: Determination of Severity and Spinal Cord Syndrome. Doctoral Thesis, Radbund University, Nijimegen, 18-22.

[3] Margaret, C. (2013) International Perspective on Spinal Cord Injury. The International Spinal Cord Society, Aylesbury, 1-10.

[4] Nils, H. (2017) Spinal Cord Injury. Physical Activity in Prevention and Treatment of Disease. Spinal Cord Injury Rehabilitation Department, Sunnaas Hospital, Nesodden, 590-593.

[5] Shehu, B.B. and Ismail, N.J. (2004) Practical Management of Spinal Cord Injury. Annals of African Medicine, 3, 46-52.

[6] Becker, D., Sadowsky, C.L. and Donald, M.C. (2003) Restoring Function after Spinal Cord Injury. The Neurologist, 9, 1-15. https://doi.org/10.1097/01.nrl.0000038587.58012.05

[7] Ziniya, M.R. (2013) Demographic Profile of Spinal Cord Injury: A Retrospective Study. Bangladesh Health Professional Institute, Dhaka, 1-21.

[8] Wagih, E.C.M. (2010) Management of Traumatic Spinal Cord Injuries: Current Standard of Care Revisited. $A C N R, 10,36-38$. https://acnr.co.uk/

[9] Hardin, E., Kobetic, R., Murray, L., Corado-Ahmed, M., et al. (2007) Walking after Spinal Cord Injury Using an Implanted FES System: A Case Report. Journal of Rehabilitation Research \& Development, 44, 333-346.

https://www.ncbi.nlm.nih.gov/pubmed/18247230 https://doi.org/10.1682/JRRD.2007.03.0333

[10] Angela, F. (2010) The Incidence and Prevalence of Spinal Cord Injury in Canada. Rick Hansen Institute, 1-7.

[11] Angela, G., David, A., Emma C., Maya D., Roger, F., et al. (2010) Management of the Older Person with a New Spinal Cord Injury. The MASCIP, 3-5. https://www.mascip.co.uk/wp

[12] Rahimi-Movaghar, et al. (2013) Epidemiology of Traumatic Spinal Cord Injury in Developing Countries: A Systematic Review. Neuroepidemiology, 41, 65-85.

[13] Ahmad, Z., Ali, M. and Abolghasem, R. (2016) A Study on Demographic Pattern, Causes and Level of Lesion in the Spinal Cord Injured Patients in Yazd City. International Journal of Medical Research and Health Sciences, 5, 447-451.

[14] Shrestha, D. (2014) Traumatic Spinal Cord Injury in Nepal. Kathmandu University 
Medical Journal, 12, 161-162. https://doi.org/10.3126/kumj.v12i3.13707

[15] Kumar, K.A., Subramanyam, B.V. and Phanidra, S.V. (2015) Demographic Pattern, Clinical Profile and Outcome of Traumatic Spinal Cord Injuries at a Tertiary Care Hospital. Romanian Neurosurgery, 29, 317-322.

https://doi.org/10.1515/romneu-2015-0042

[16] Conran, J. (2016) Traumatic Spinal Cord Injury in South Africa and Sweden: Epidemiological Features and Functioning. Karolinska Institute, Solna, 1-8.

[17] Bartel, H.M.A., Hosman, J.F. and Henk, V. (2013) Design of Cosmic: Randomized Multicenter Controlled Trial Comparing Conservative or Early Surgical Management of Incomplete Cervical Cord Syndrome without Instability. BMC Musculoskeletal Disorders, 14, 52. https://doi.org/10.1186/1471-2474-14-52

[18] Hwa, J.L., Hwan, S.K. and Kyoung, H.N. (2013) Neurologic Outcome of Laminoplasty for Acute Traumatic Spinal Cord Injury without Instability. Korean Journal of Spine, 10, 133-137. https://doi.org/10.14245/kjs.2013.10.3.133 